\title{
The Carbon Sequestration Potential of Regenerative Farming Practices in South Carolina, USA
}

\author{
Gabriel J. Kenne, Robin W. Kloot \\ Soil and Environmental Health Lab, Department of Environmental Health Sciences, Arnold School of Public Health, \\ University of South Carolina, Columbia, SC, USA \\ Email: kloot@mailbox.sc.edu
}

How to cite this paper: Kenne, G.J. and Kloot, R.W. (2019) The Carbon Sequestration Potential of Regenerative Farming Practices in South Carolina, USA. American Journal of Climate Change, 8, 157-172. https://doi.org/10.4236/ajcc.2019.82009

Received: February 10, 2019

Accepted: April 5, 2019

Published: April 8, 2019

Copyright $\odot 2019$ by author(s) and Scientific Research Publishing Inc. This work is licensed under the Creative Commons Attribution International License (CC BY 4.0).

http://creativecommons.org/licenses/by/4.0/ (c) (i) Open Access

\begin{abstract}
Current production agriculture systems typically focus on yield outcomes at all costs. By shifting to best management practices based on regenerative farming principles, however, agricultural systems worldwide could maintain or even improve yields while sequestering atmospheric carbon (C) into soil organic matter (SOM). To demonstrate the effectiveness of regenerative principles at simultaneously benefiting agriculture and reducing greenhouse gasses, their $\mathrm{C}$ sequestration potential was examined through SOM data from 486 soil sampling locations from multiple farms throughout the coastal plains of South Carolina. These data were compared over varying multiple-year periods between 2013 and 2017 as their land management practices shifted from conventional methods to those based on the regenerative-based practice of cover cropping. The implementation of cover crops in crop rotations resulted in statistically significant mean SOM percentage increases of $0.11(\mathrm{p} \leq 0.001)$, 0.11 ( $\mathrm{p} \leq 0.001$ ), and 0.55 ( $\mathrm{p} \leq 0.001)$ for sampling sites converted into rotations utilizing cover crops for two, three, and four years, respectively. When averaged out per year for each sampling group, this results in an average of 622,425 , and $1584 \mathrm{lbs}$./acre/year of $\mathrm{C}$ fixed from the atmosphere and retained in the soil as organic matter. Increases were observed across all soil types sampled in the study with soil texture not significantly influencing a soils' ability to increase soil OM or sequester atmospheric $\mathrm{C}$ through cover crop implementation. The calculations based on the coastal plains' soils studied here demonstrate the promising potential of the application of regenerative farming principles to not only restore degraded biodiversity, recycle nutrients, improve farm profitability, and reduce chemical inputs, but also to sequester atmospheric $\mathrm{C}$ and simultaneously help reduce the effect of global climate change while creating healthy soils.
\end{abstract}




\section{Keywords}

Carbon Sequestration, Soil Health, Regenerative Agriculture, Cover

Crops, Climate Change

\section{Introduction}

Terrestrial ecosystems contributed to increasing atmospheric carbon dioxide $\left(\mathrm{CO}_{2}\right)$ prior to the industrial era, but the rates of atmospheric $\mathrm{CO}_{2}$ input have since increased $\sim 20 \times$ due not only to industrialization and fossil fuel combustion, but also from land-use conversion to agriculture and the introduction of industrial farming's use of synthetic chemicals and high disturbance land management [1] [2] [3] [4]. Soils themselves contribute to atmospheric C levels, but these inputs vary widely across the planet and depend on natural variations in soil properties and climate in addition to anthropogenic influences from land-use conversion and land management practices [4]. With an estimated total C pool of $\sim 2200 \mathrm{Pg}$, soils store as much as 4 -times the $\mathrm{C}$ of plant and atmospheric pools [5] [6] [7]. Land management practices associated with industrial and production agriculture remove this carbon stock from the Earth not only via the burning of fossil fuels to run a wide range of heavy equipment, but also through extractive practices of monocropping and fallow periods, and extensive tilling that exposes existing soil organic matter (SOM) to increased microbial oxidation and decomposition [8]. These agricultural practices negatively affect SOM pools in a bidirectional manner; first, tillage increases the speed of crop residue decomposition by soil microbes and their subsequent $\mathrm{CO}_{2}$ release from respiration; and second, leaving fields fallow between cash crops eliminates the opportunity to fix new $\mathrm{C}$ into the terrestrial system to generate organic matter. The loss of SOM from the conversion of natural to agricultural ecosystems has been well observed and intensively studied throughout history and has been shown to cause the most rapid losses, near $50 \%$ of the SOM in temperate zones, within the first 25 years of the land use transition [2] [9] [10] [11]. Changes in these destructive agricultural land management practices offer the potential to shift away from this lopsided movement of soil C into the atmosphere and subsequently reduce the need for additional land-use conversion by slowing, or over time eliminating, the loss of current farm/grazing land.

The evolution of regenerative agriculture principles in recent years offers solutions to many of the unintended, self-inflicted consequences that stem from conventional land management, such as soil degradation and runoff, and the increased dependency of synthetic chemicals and intense tillage due to loss of soil biological function and natural nutrient cycling abilities [12] [13] [14] [15]. Regenerative principles focus on building soil organic matter and promoting biodiversity through management practices that include reduced tillage and synthetic inputs, eliminating bare soil and fallow events, the implementation of 
multispecies cover crops in rotations to foster plant diversity, and the use of rotational grazing or animal manures [1] [9] [16]. By managing farmland to foster healthy, living soils, the resulting regenerative systems are able to combat the problems created by conventional land management while also creating opportunities to reduce the amount of $\mathrm{CO}_{2}$ respired into the atmosphere through soil microbial metabolism, and to move $\mathrm{C}$ from the atmosphere back into the soil [9] [11] [17] [18]. Additionally, these management practices also often require less frequent use of farm equipment, therefore, reducing soil compaction and agricultural emissions from fossil fuel consumption.

The act of harvesting sunlight through cover crop use when conventional fields are fallow results in more growing days in which $\mathrm{CO}_{2}$ is photosynthetically removed from the atmosphere. Additional benefits of cover cropping, especially when using multi-species cover crop mixes, include nitrogen $(\mathrm{N})$ scavenging, reduction in erosion, weed suppression, increased nutrient recycling, protection of water quality, enhanced wildlife habitat, and increased soil health through adding $\mathrm{C}$ to the soil not only as cover crop residues left to cover the soil, but also as root exudates from living plants, which attract soil microbes to the rhizosphere [9] [19] [20]. These root exudates are then microbially metabolized into different organic forms of carbon and other nutrients that mutualistically feed the plants and microbes alike. Reduction of tillage allows these terrestrial deposits of $\mathrm{C}$ to decompose at a slower rate, increasing soil fertility and structure while reducing erosion and the release of $\mathrm{CO}_{2}$ into the atmosphere from surface microbial metabolism [8] [20].

In the loamy sand and sandy loam soils of the coastal plains of South Carolina, a warm climate provides the opportunity for almost year-round growing seasons for various crops. While warm and cool growing seasons offer more frequent opportunity for conventional management practices to degrade soil quality, it also creates additional opportunities for regenerative management practices to increase crop- and bio-diversity through multispecies cover crop rotations in both the warm and cool seasons. Using data from three different soil sample datasets from throughout the SC coastal plains region, the effect of regenerative-based management practices on SOM was observed for 2-, 3-, and 4 -year durations from the implementation of diverse cover cropping systems. SOM values were then used to quantify changes in soil carbon over time to estimate the atmospheric $\mathrm{C}$-sequestration potential of regenerative farming practices in SC.

\section{Sample Collection \& Analysis}

\subsection{Sample Locations and Collection}

Composite standard 6.2-inch deep soil samples were collected from a total of 502 sampling locations throughout Dillon and Marlboro Counties in the coastal plains of South Carolina, USA. All sampling locations have been under long-term conservation tillage regimes only utilizing subsoil and/or strip tillage 
once or twice each year. The farms sampled in this study all began implementing multispecies cover crops at the start of their respective project (described below). By implementing these regenerative-based practices, the involved farmers have substantially limited or completely eliminated traditional fertilizer and other chemical applications, typically only applying $\mathrm{N}$ fertilizer as needed.

Data were collected from these sampling locations for three separate projects that have ranged in duration from two to four years, one of which concluded at the end of 2017 and two of which are ongoing. Sample set locations are shown in Figure 1 and individual project descriptions can be found in Table 1. Thirteen of the 502 sampling locations were from a 2013 SC NRCS Conservation Innovation Grant (CIG) titled "Using $\mathrm{CO}_{2}$-Burst Tests to Measure On-Farm Plant Available Nitrogen from Cover Cropped Soils in South Carolina" and were

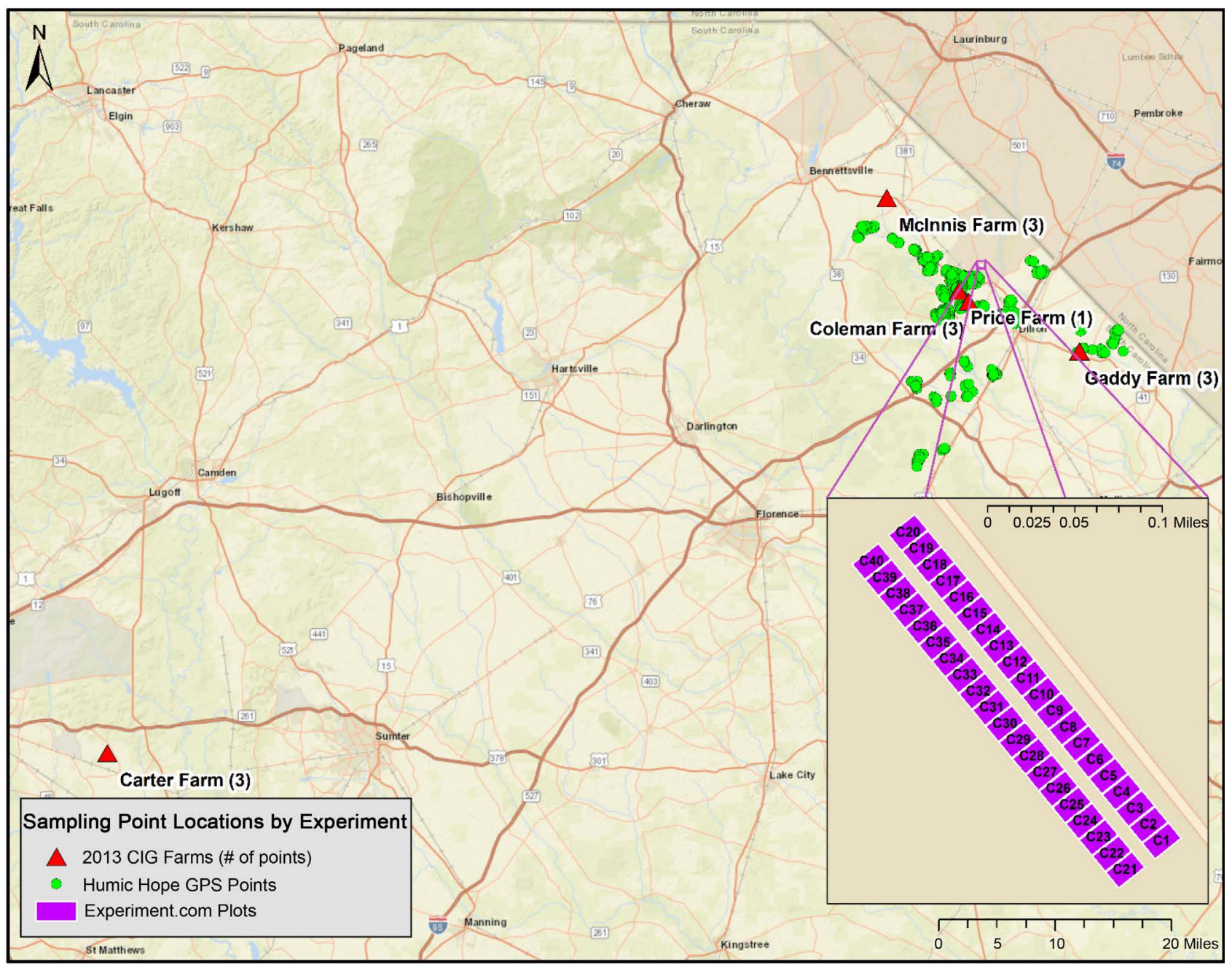

Figure 1. Map of sampling point locations and farms. locations of farms containing the thirteen 2013 CIG farms are shown as triangles on the map with the number of sampling zones (zoned by soil type) in parentheses. The 433 Humic Hope GPS located sampling sites are marked as circles on the map mostly in Dillon and Marlboro Counties near the NC border. The 40 Experiment.com plots (CC01-CC40) adjacent to Highway 57 northwest of Little Rock, SC are displayed on the map insert. Map Sources: Esri, HERE, DeLorme, USGS, Intermap, INCREMENT P, NRCan, Esri Japan, M ETI, Esri China (Hong Kong), Esri Korea, Esri (Thailand), MapmyIndia, NGCC, (C) OpenStreetMap contributors, and the GIS User Community. 
Table 1. Description of individual projects and sampling methods used. The project names, duration, number and type of samples used in the observational study of soil OM. Outliers removed from each sample set by Anderson-Darling Normality Tests are shown in the far-right column.

\begin{tabular}{ccccc}
\hline Project Name & $\begin{array}{c}\text { Duration } \\
\text { (years) }\end{array}$ & $\begin{array}{c}\text { \# of Samples } \\
\text { (n) }\end{array}$ & $\begin{array}{c}\text { Description of } \\
\text { sampling method. }\end{array}$ & $\begin{array}{c}\text { Outliers } \\
\text { Removed }\end{array}$ \\
\hline Humic Hope & 2 & 449 & $15^{\prime}$ radius around GPS points & 16 \\
Experiment.com & 3 & 40 & $60^{\prime} \times 100^{\prime}$ plot composites & 0 \\
2013 CIG & 4 & 13 & Zone composites by soil series & 0 \\
\hline
\end{tabular}

sampled biannually a total of 9 times between Nov. 2013 and Nov. 2017. 40 sampling locations were from two experiment.com crowd funded research projects titled "How much Fertilizer do We Really Need?", and "No But Seriously, How Much Fertilizer Do We Really Need?" through the University of South Carolina and were sampled a total of 7 times biannually between Dec. 2014 and Nov. 2017. The remaining 449 locations were private crop consulting sample points monitored between Oct. 2015 and Nov. 2017 as needed by Humic Hope, LLC throughout cash and cover crop rotations. These three sampling groups result in 4-, 3-, and 2-year long sampling groups, respectively, allowing for a staggered temporal observation of OM change.

The 2013 CIG samples were collected as composite zone samples based on soil series, the experiment.com samples were all from $60^{\prime} \times 100^{\prime}$ plot composites, and the Humic Hope samples were all from within a $15^{\prime}$ radius of specific GPS points. All points and/or field plots were flagged and GPS logged for consistent sampling throughout each project's duration. Initial and final samples for each site used in this study were taken at the same time of year to eliminate bias from seasonal fluctuations. All composite soil samples were sent to Clemson University's Agricultural Services Laboratory (Clemson, SC, USA) for standard soil tests and \% organic matter (OM). SOM is nonhomogenous, not chemically well-defined, and cannot be directly measured [11]; so here data from loss on ignition (LOI) protocols was used as a proxy indicator of total SOM. Percentage SOM data was compiled for each of the three individual sampling groups initial and final/most recent sampling date to represent 2-, 3-, and 4-year changes in SOM after switching from conventional fallow periods to regenerative multispecies cover cropping practices.

\subsection{Statistical Analysis}

$\% \mathrm{OM}$ data for each of the three groups were compiled for their respective initial sampling and final sampling events and the total OM change between those sampling events for each sampling point was calculated. Based on an Anderson Darling Normality Test, a total of $16 \mathrm{OM}$ change values were determined to be outliers and were excluded from the data analysis (Minitab@ 18 Statistical Software, State College, PA, USA). All 16 outliers were from the large two-year, 449 sample-set, reducing that sample set size to 433 and the total combined size of all 
three experiments to 486 . By testing the change in OM for normality rather than individual initial and final sampling point data, sampling points where only one sampling event was outside of the acceptable range were detected and removed, eliminating the removal and biasing of sampling points in higher or lower $\% \mathrm{OM}$ soils that have consistently higher or lower OM values throughout the sampling time frame. Some of the statistically removed data points were visually obvious as data entry errors in soil test reports, such as missing decimal points within values. These points were left removed from the analysis as to not create additional bias.

Paired t-tests were performed on the initial and final OM percentages for the entire dataset as a whole, and on each sampling group independently. Additionally, the OM change per year was calculated based on the initial and final OM measures for all individual samples from each of the three experiments and used to perform a one-way ANOVA based on soil texture. The resulting t-test and ANOVA means were then used to calculate OM and soil organic carbon (SOC) quantities per unit area using standard estimates of 2,000,000 lbs. of soil per acre, and $58 \%$ soil C content [8] [17].

\section{Results}

Paired t-tests on the initial and final sampling values for the entire dataset resulted in a mean \%OM increase of 0.1191 ( $\mathrm{p} \leq 0.001$ ). Without accounting for differences in time since implementation of cover cropping between groups, this change in \%OM translates to a total OM increase of $2382 \mathrm{lbs} . / \mathrm{ac}(2670 \mathrm{~kg} / \mathrm{ha})$ for a sampling area that totals roughly 5000 acres (Figure 2). When split into their respective sampling groups, the 4-year 2013 CIG sample set did not have any outlying data points removed, leaving the total sample number at 13 . Paired t-tests on this sample set resulted in a mean \%OM increase of $0.5462(\mathrm{p} \leq 0.001)$, translating to an average increase of roughly $2731 \mathrm{lbs}$. OM/ac/year for the 4 -year sampling duration. The 3-year experiment.com sample set had a larger sample size of 40 with no outlying data points removed and had a mean \%OM increase of 0.11 ( $\mathrm{p} \leq 0.001$ ), translating to roughly $733 \mathrm{lbs}$. OM/ac/year. The final 2-year Humic Hope sample set had a substantially larger sample number of 433 sampling points after 16 outliers were removed. This group had a mean \%OM change of 0.1072 ( $\mathrm{p} \leq 0.001$ ), translating to roughly $1072 \mathrm{lbs}$. OM/ac/year. Changes in each individual group are shown in Figure 3.

The mean increase in soil $\mathrm{OM}$ for each individual groups t-test above was then used to calculate $\mathrm{OM}$ and soil organic carbon (SOC) quantities per unit area per year assuming the estimated average values of 2,000,000 lbs. of soil per acre and a soil C content of 58\% [8] [17]. Table 2 shows the soil OM and SOC quantities for each sampling group per year as well as the entire dataset. Average increases of 1072; 733; and $2731 \mathrm{lbs}$. OM/acre/year correspond to 622; 425; and $1584 \mathrm{lbs}$. C/acre/year sequestered from the atmosphere and deposited into the soil from the 2-, 3-, and 4-year sampling groups, respectively. 


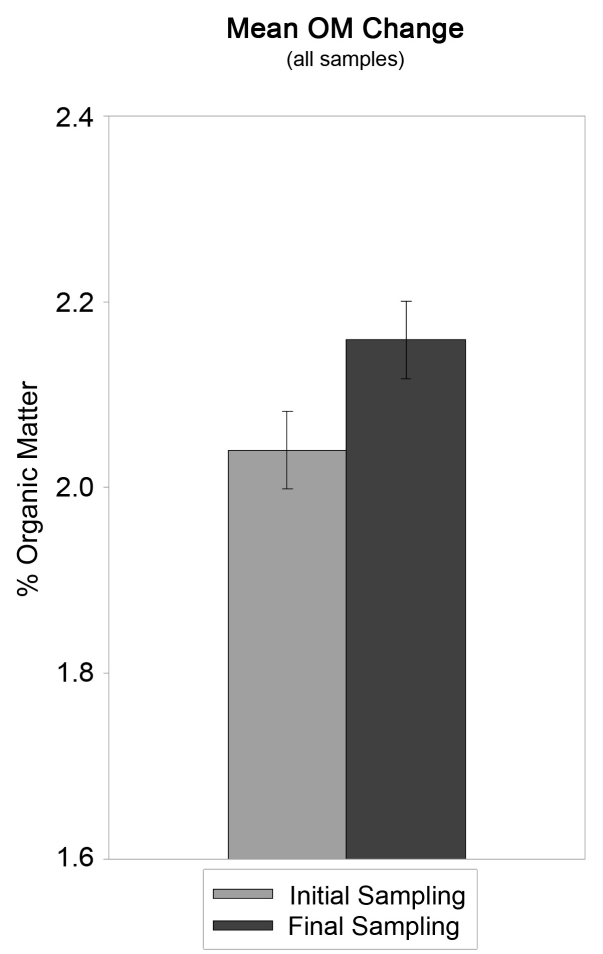

Figure 2. Total change in soil \%OM for all samples. The mean soil \%OM for all sampling locations from all sampling groups at the initial sampling event and at the final/most recent sampling event. Without accounting for time differences since cover crop implementation between groups, we observed a total mean \%OM increase of 0.1191 , which is equivalent to a mean increase in soil OM of $2384 \mathrm{lbs} . /$ acre $(2670 \mathrm{~kg} / \mathrm{ha})$.

\section{Change in Organic Matter by Sampling Group}

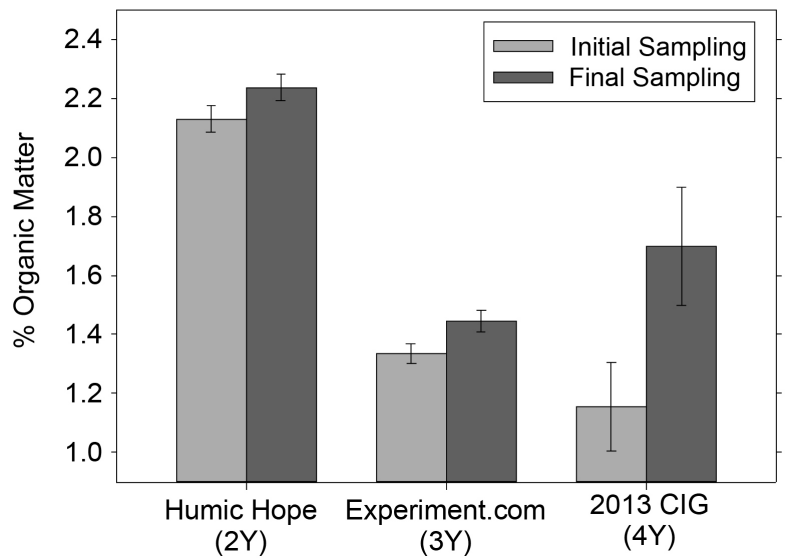

Figure 3. \%OM change by sampling group. Bars represent the initial and final/most recent mean \% soil OM values by sampling group. The 2-, 3-, and 4 -year sampling groups all had statistically significant increases in \%OM ( $\mathrm{p} \leq$ 0.001 for all 3 groups). The large error bars (SEM) in the 4 -year group are likely due to the small sample size of that group, which is inconsistent between sampling groups and likely a confounder to any observed temporal relationship between the time since regenerative management initiation and soil \%OM. 
Table 2. Mean increases in soil OM and C by sampling group. The mean OM changes by sampling group are shown here and include calculations into representative $\mathrm{OM}$ and $\mathrm{C}$ changes in lbs/ac/year and the equivalent $\mathrm{kg} / \mathrm{ha} / \mathrm{year}$. These calculations are based on assumptions of an average of 2,000,000 lbs. of soil/ac and a soil C content of 58\% [8] [17].

\begin{tabular}{cccccc}
\hline \multirow{2}{*}{ Project Name (Description) } & \multicolumn{3}{c}{ Mean OM Change } & \multicolumn{2}{c}{ Mean C Change } \\
\cline { 2 - 6 } & \%/year & lbs/ac/year & $\mathrm{kg} / \mathrm{ha} /$ year & lbs/ac/year & $\mathbf{k g} / \mathrm{ha} /$ year \\
\hline $\begin{array}{c}\text { Humic Hope } \\
(\mathrm{n}=433 ; \text {-years })\end{array}$ & 0.054 & 1072 & 1201 & 622 & 696 \\
$\begin{array}{c}\text { Experiment.com } \\
(\mathrm{n}=40 ; 3 \text {-years })\end{array}$ & 0.037 & 733 & 821 & 425 & 476 \\
$\begin{array}{c}\text { 2013 CIG (n=13; 4-years }) \\
\text { (n }\end{array}$ & 0.137 & 2731 & 3059 & 1584 & 1774 \\
\hline
\end{tabular}

One-way ANOVA analysis of soil texture characteristics on the mean OM changes showed no significant differences between the OM increases observed in the 7 soil textures sampled. One single sample in the large Humic Hope data set was from a sandy clay loam and had a mean increase of $7000 \mathrm{lbs}$. OM/ac/year but was excluded from additional analysis and interpretation due to that soil texture only having a single sample $(n=1)$. This resulted in 6 soil textures (sand, loamy find sand, loamy sand, sandy loam, fine sandy loam, and loam) for analysis with annual mean rates of change for ranging from $600 \mathrm{lbs}$. OM/ac/year in fine sandy loams to $1800 \mathrm{lbs}$. OM/ac/year in sands. Table 3 shows the mean percentage and $\mathrm{OM} / \mathrm{ac}$ rates of change per year for each soil texture.

\section{Discussion}

\subsection{Agricultural Implications}

Conventional agricultural practices generally deplete soil OM content through aggressive monocropping, tillage, fallow periods, and synthetic chemical use [9] [20] [21]. Tilling exposes additional soil surface area to microbial oxidation, increasing the rate of SOM decomposition [8] [20] and increasing microbial respiration and release of $\mathrm{CO}_{2}$ into the atmosphere, which is why conventional agricultural land management generates a temporal decline in SOM, especially if residues and cover crops are not utilized to resupply organic material to SOM-generating microbes. Understanding the ways in which these soil microbes regulate soil $\mathrm{C}$ and the relationships they have with plant root systems are important to increasing agricultural efficiency and reducing atmospheric $\mathrm{CO}_{2}$ inputs [22]. The use of mixtures of multiple species within a cover crop is known to increase SOC more than a single-species cover crops would due to increased belowground biomass and diversity [20] [23]. Additionally, a recent study from Sokol and Bradford [24] has shown that microbial formation of stable soil C is much more efficient through the rhizosphere than in bulk soil, providing experimental support for the use of multispecies cover crops that can generate a diverse rhizosphere during traditionally fallow periods comprised of much less efficient bulk soil between cash crops. All field sites observed in this study have 
Table 3. Mean annual rates of change in soil OM by soil texture. The mean rates of change in soil OM/year by soil texture. No statistically significant differences were found between the textures, even when the single sandy clay loam sample was excluded from analysis due to its small sample size (n). Values are shown as \%OM change and as lbs. $\mathrm{OM} / \mathrm{ac}$ based on $2,000,000 \mathrm{lbs}$. of soil/ac [8].

\begin{tabular}{cccc}
\hline Soil Texture & $\mathbf{n}$ & Mean \%OM Change/Year & lbs. OM/ac/yr \\
\hline Sandy Clay Loam & 1 & 0.35 & 7000 \\
Sand & 15 & 0.09 & 1800 \\
Loamy Fine Sand & 129 & 0.06 & 1200 \\
Loamy Sand & 108 & 0.06 & 1276 \\
Sandy Loam & 68 & 0.03 & 648 \\
Fine Sandy Loam & 136 & 0.03 & 600 \\
Loam & 29 & 0.07 & 1328 \\
\hline
\end{tabular}

shifted from conventional fallow periods into the regenerative-based practice of using multispecies cover crops at the time of initial sampling, allowing the change in soil OM due to cover crop use over time to be observed.

The initial intent of the projects included in this study was not to examine terrestrial and atmospheric $\mathrm{C}$ exchanges but was for purposes strictly pertaining to soil fertility and agricultural productivity. Because of these initial scopes, additional information useful for $\mathrm{C}$ sequestration analysis, such as atmospheric $\mathrm{CO}_{2}$ levels at sampling sites, cash and cover crop biomass, or number of growing days, was not recorded during any of the three projects analyzed here. Data presented here is limited to standard agricultural soil sampling methods pertaining to physical and chemical analysis of composite 6.2 " deep soil samples to be representative of broad field locations. Despite the absence of additional atmospheric data, the \%OM data provided by these standard agricultural samples has generated a range of potential $\mathrm{C}$ sequestration rate increases based on the implementation of cover crops during traditionally fallow periods.

Data used in this study came from a total of nine different farms throughout the coastal plains region of SC (Humic Hope $=3$ farms; experiment.com $=1$ farm; 2013 CIG $=5$ farms), each of which have slightly different soil profiles and intensities of regenerative-based land management. Through reduced tillage and chemical inputs, along with the introduction of multi-species cover crops between cash crops, the fields in this current study were able to generate an average collective soil C input of $1382 \mathrm{lbs}$./ac in no less than two years of regenerative-based management. When divided up into sampling groups based on time since implementing cover crops (2-, 3-, and 4-years), increases in soil \%OM ranged from 733 - $2731 \mathrm{lbs}$. OM/ac/year (Figure 3), pertaining to average soil C increases of 425 - $1584 \mathrm{lbs}$./ac/year. While we hypothesize that longer durations of regenerative farming practices will increase soil OM percentages and therefore, soil C, this observational dataset lacks any conventionally managed control plot(s) and is not complete enough to test that hypothesis. Also, while a majority of the Humic Hope acreage saw cover crops or cool-season crops in this 
two-year sample period, some land was fallow over the cool season. Additional monitoring of larger sample sets, such as the current 2-year Humic Hope data set, and incorporation of additional conventionally managed controls on these soil types through upcoming years will provide a much more accurate, experimental indication of rates of soil OM change from regenerative-based farming practices.

A traditional 6.2-inch furrow-slice of loamy sand soil, typical in the coastal plains of South Carolina, with $1 \%$ organic matter and an average bulk density of $1.55 \mathrm{~g} / \mathrm{cm}^{3}$ will have roughly $21,000 \mathrm{lbs}$. of organic matter [25]. This means that a SOM increase of only $0.1 \%$ would be an addition of 2100 lbs. of new organic matter per acre. The 2012 USDA Census of Agriculture reports the total cropland in SC to be 1,967,288 acres with an average farm size of 197 acres [26]. Based on our observed top 6.2" average SOC change values, this creates potential atmospheric $\mathrm{C}$ sequestration of 50 - 156 tons per year for a single average farm in SC, and 500,647 - 1,558,092 tons statewide if regenerative practices were implemented. These estimates are based solely on coastal plans soils, however, and actual values will differ due to varying soil types throughout the state.

Fine silts and clays, or "heavy" soils are more likely to have higher organic matter content than "lighter", sandy soils like those in the coastal plains of SC [27]. This phenomenon has been shown true for soils throughout SC, from "heavy" piedmont soils to "light", sandy coastal soils, through compiled data provided by Humic Hope, LLC from over 2100 soil samples from across the state and can be seen in Supplementary Table S1. Categorizing OM samples in this study by their soil texture resulted in a range of seven differing soil textures; a sandy clay loam, sands, loamy fine sands, loamy sands, sandy loams, fine sandy loams, and loams as defined by the Soil Web Survey [28]. Only one sample in the study was from a sandy clay loam, so that texture was excluded from comparison against other textures mean values due to its limiting sample size ( $\mathrm{n}=$ 1). The means of the final recorded OM values for these soil textures were compared and coincides with the above phenomenon of "light" and "heavy" soils, but when the rates of OM change per year for these textures was calculated and analyzed using a one-way ANOVA, the changes were variable, ranging from 600 lbs. OM/ac/year to $1800 \mathrm{lbs}$./ac/year, but no significant differences were found between the six soil textures (Table 3). Additionally, while the differences were not significant, the variability in the rates of change did not follow the same trend of increasing OM from "light" to "heavy" soils observed from total OM sample measures above. This variability of OM rates of change demonstrates that soil texture did not necessarily amplify, limit, or restrict its ability to improve OM content and sequester C. This variability in annual OM rates of change for the different soil types suggests that geographical and environmental factors that can be highly variable between sampling points, such as relief and rainfall, may be more influential on the atmospheric $\mathrm{C}$ sequestration potential of soils than a soils physical texture, even when they are managed using regenerative-based practices. Figure 4 shows the differences in $\mathrm{C}$ sequestration rates 
Mean Final Soil C Values and Annual Increases Based on Soil Texture

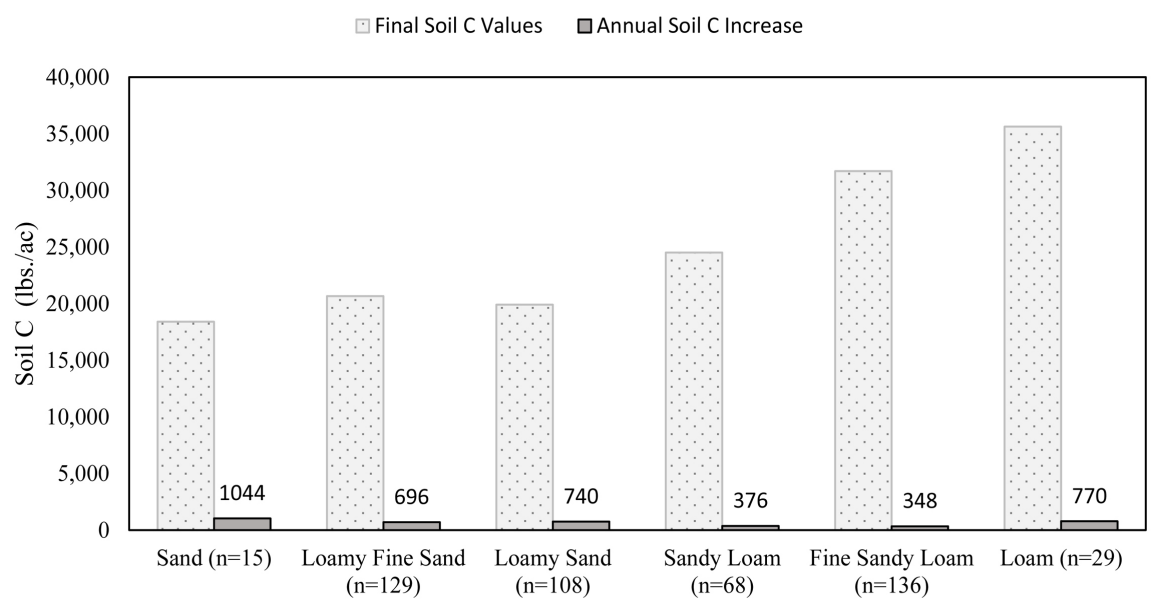

Figure 4. Mean final soil $\mathrm{C}$ values and annual rates of soil $\mathrm{C}$ increase by soil texture. Final calculated soil C means based on 2,000,000 lbs. of soil/ac and a soil C content of 58\% [8] [17] are shown adjacent to each soil's calculated Annual Rate of Change in soil C (actual values shown above bar). Increasing soil $\mathrm{C}$ content along the spectrum from lighter sands to heavier loams was expected, but the observed variability in the Mean Annual Soil C Increases supports the concept that management practices are capable of increasing soil $\mathrm{C}$ content regardless of texture, and that geographical and environmental factors may play more important roles in $\mathrm{C}$ sequestration potential than a soils physical texture. The total sample size of each soil texture is shown in parentheses on the $\mathrm{X}$-axis.

between six of the seven soil textures from this study and the final calculated soil C levels for the respective soil textures.

This data supports the concept that, regardless of soil texture, the transition from conventional agricultural land management to regenerative-based practices has the potential to sequester a substantial amount of atmospheric $\mathrm{C}$ in addition to creating soil hydrological and biological health benefits that influence crop health and yield. These benefits have been seen and demonstrated first-hand by the farmers involved in this project, who since the implementation of cover crop use have had some of their best recorded wheat and soybean yields. These improved yields also show that increasing $\mathrm{C}$ sequestration through agricultural management practices doesn't have to be at the expense of farmers, but rather creates additional benefit.

\subsection{Relation to Cultural Barriers}

The purpose of the soil sampling that acquired the data used in this analysis was not to generate new or practical knowledge of the impacts of land management and cover crop use on $\mathrm{C}$ sequestration, but was rather to acquire data on the impacts of these practices on soil fertility and how changing management practices could provide financial and environmental benefits to farmers and producers in SC. Current paradigms of production agriculture displace monetary and environmental burdens onto farmers and producers who are pressured to generate the highest possible yields at all cost. Through approaching these farmers 
and producers with a potential ease some of these burdens by contributing to sustainable fertility on their land though cover crop implementation, subsequent analysis of soil fertility data only later revealed the additional benefit of these practices to increased carbon sequestration via increasing SOM percentages.

Despite the fact that agriculture could substantially benefit from an increased knowledge-base regarding climate due to the obvious link between climate and on-farm decision-making and yield outcomes [29] [30] [31], farmers tend to be conservative individuals who are often suspicious or apprehensive of environmentally motivated interventions or research intentions [18]. Keeping these cultural perspectives in mind, the necessary future research concerning the impacts of agricultural practices on climate change should be pursued in a manner that is respective to farmers perspective and is aimed at benefitting their involvement and bottom line to alleviate not only global climate burdens, but to acknowledge their direct needs by improving the quality and fertility of their soil. Farmers are particularly vulnerable to climate variability since their livelihood is dependent on it [29] [32], so a land management strategy targeted at relieving the burdens of industrial agriculture, while simultaneously alleviating the global burdens of climate change will directly benefit the farmers/producers while increasing their understanding of the significance of climate change on their operation. Creation of educational and mutually beneficial relationships will also increase the likelihood of farmer involvement in future research.

\section{Limitations}

The observed changes in soil OM percent shown here and their respective projected sequestered atmospheric $\mathrm{C}$ are calculated based on average values of soil bulk density rather than specific measurements that were unavailable for the sample sites used in this analysis, limiting the specificity of $\mathrm{C}$ sequestration potential to a generalized value for coastal plains soils. Additionally, data presented here do not include two additional factors that would likely further increase the quantity of total atmospheric $\mathrm{C}$ sequestered from multispecies cover crop use. Firstly, while the above values account for the transition of atmospheric $\mathrm{C}$ to terrestrial $\mathrm{C}$ as SOM, they do not consider the additional terrestrial $\mathrm{C}$ in the form of soil inorganic carbon (SIC) and the changes in these concentrations over time under regenerative land management practices. SIC is a mineral form of $\mathrm{C}$ in the soil, made up of various forms of carbonate $\left[\mathrm{CaCO}_{3}, \mathrm{CaMg}\left(\mathrm{CO}_{3}\right)_{2}\right.$, $\mathrm{Na}_{2} \mathrm{CO}_{3}, \mathrm{FeCO}_{2}$ ]. Lorenz and Lal [33] estimate SIC stocks in arid regions to be $700-1700 \mathrm{Pg}$ in the top meter of soil, but these stocks are not well studied or defined in temperate regions or at depth. While SIC is known to be a large terrestrial $\mathrm{C}$ pool and plays an important role in the global C cycle, especially in arid and semi-arid environments, there is debate on the movement of $\mathrm{C}$ through this system and the potential effects it could have on atmospheric $\mathrm{CO}_{2}$ [34] [35].

The second limitation of this study is that the data were collected using standard soil sampling methods that only use and test the traditional top 6.2-inch 
furrow-slice of soil at any given sampling point. The roots of many cash and cover crops go well beyond this 6.2" depth, creating a much larger potential area for atmospheric $\mathrm{C}$ deposition into the terrestrial environment that is not accounted for in this observational study. Depth samples were taken on a random selection of 12 of the 40 plots from the 3-year sampling group during this study and average \%OM values for different depths up to 24 " show that while there is a decline in \%OM below the top 6" (Table 4), a surprising amount of OM is present in the subsoil. The observed decline in \%OM with depth is expected and has been shown to be more dramatic in no-till systems due to the increased levels of SOM near the surface [21].

\section{Conclusions}

The mean SOM and soil $\mathrm{C}$ values across all sampling points as a whole and within each duration group have all increased significantly in as few as 2 years under regenerative agricultural management practices across seven different soil textures, removing an average of 425 - $1584 \mathrm{lbs}$. atmospheric C/acre/year in the coastal plains of SC. While the intent of the soil sampling used in this study was not to understand terrestrial and atmospheric $\mathrm{C}$ exchanges but was rather to better understand soil fertility while transitioning from conventional fallow periods to regenerative cover cropping practices, it is quite clear that in addition to the agricultural benefits to soil health and structure, the implementation of these practices fosters an additional benefit of atmospheric $\mathrm{C}$ sequestration. To fully understand the carbon sequestration potential of regenerative agriculture, long-term prospective studies focused on atmospheric and terrestrial $\mathrm{C}$ need to be conducted with conventionally managed controls and include depth profiles and SIC pools. Farmers' concerns, however, must be integrated into the development of this future climate-related research, such as the inclusion and translation of research goals into short- and long-term crop impacts, as well as on-farm education and interpretation of data. This will acknowledge the perspective of farmers and foster future participation in climate- and environment-driven research.

The key element in this study is the use of regenerative farming practices to reverse the direction of $\mathrm{C}$ flow in atmospheric and terrestrial ecosystems. Fostering soil biology is key to this shift and is an effective way to increase SOM, but

Table 4. \%OM at depth in a random sampling from the 3-year (Experiment.com) plots. 12 of the 40 plots in this sampling set had depth profiles taken in 2017 that were split into three depth ranges $(0-6$ ", $6-12$ ", and $12-24$ ") that were tested for standard soil nutrients and \%OM, revealing the presence of soil OM well below the standard 6.2" depth used in traditional soil testing and additional potential for atmospheric $\mathrm{C}$ sequestration.

\begin{tabular}{cc}
\hline Soil Profile Depth & \%OM \\
\hline $0-6 "$ & 1.9 \\
$6-12 "$ & 1.3 \\
$12-24^{\prime \prime}$ & 1.6
\end{tabular}


this process itself is actually dependent on plant communities sequestering atmospheric $\mathrm{CO}_{2}$ and generating root exudates for microbes [6] [16]. Implementation of cover cropping allows this exchange to occur, undisturbed by tillage and chemical use, for more photosynthetically active days than conventional farming, resulting in a significant increase in the amount of $\mathrm{CO}_{2}$ sequestered from the atmosphere and deposited into soil organic matter that will further foster healthy agriculture. Shifting to such regenerative practices creates a relevant benefit to farmers while simultaneously creating a global benefit from their $\mathrm{C}$ sequestration potential.

\section{Conflicts of Interest}

The authors declare no conflicts of interest regarding the publication of this paper.

\section{References}

[1] Lal, R. (2004) Soil Carbon Sequestration Impacts on Global Climate Change and Food Security. Science, 304, 1632-1637.

[2] Paustian, K., Collins, H.P. and Paul, E.A. (1996) Management Controls on Soil Carbon. In: Paul, E.A., et al., Eds., Soil Organic Matter in Temperate Agroecosystems, Long-Term Experiments in North America, CRC Press, New York, 15-42.

[3] Ruddiman, W. (2003) The Anthropogenic Greenhouse Era Began Thousands of Years Ago. Climate Change, 61, 261-293.

[4] Sanderman, J., Hengl, T. and Fiske, G.J. (2017) Soil Carbon Debt of 12,000 Years of Human Land Use. PNAS, 114, 9575-9580.

[5] Liu, Y., Delgado-Baquerizo, M., Wang, J., Hu, H., Yang, Z. and He, J. (2018) New Insights into the Role of Microbial Community Composition in Driving Soil Respiration Rates. Soil Biology \& Biochemistry, 118, 35-41.

[6] Batjes, N.H. (1996) Total Carbon and Nitrogen in the Soils of the World. European Journal of Soil Science, 47, 151-163.

[7] IPCC (2013) Climate Change 2013: The Physical Science Basis. Contribution of Working Group I to the Fifth Assessment Report of the Intergovernmental Panel on Climate Change. Cambridge University Press, Cambridge and New York.

[8] Franzmeier, D.P., McFee, W.W., Graveel, J.G. and Kohnke, H. (2016) Soil Science Simplified. 5th Edition, Waveland Press, Inc., Long Grove.

[9] Matson, P.A., Parton, W.J., Power, A.G. and Swift, M.J. (1997) Agricultural Intensification and Ecosystem Properties. Science, 277, 504-509.

[10] Flach, K.W., Barnwell Jr., T.O. and Crosson, P. (1996) Impacts of Agriculture on Atmospheric Carbon Dioxide, in Soil Organic Matter in Temperate Agroecosystems: Long-Term Experiments in North America. CRC Press, New York.

[11] Weil, R.R. and Magdoff, F. (2004) Significance of Soil Organic Matter to Soil Quality and Health. In: Weil, R.R. and Magdoff, R., Eds., Soil Organic Matter in Sustainable Agriculture, CRC Press, New York, 1-43.

[12] Montgomery, D.R. (2007) Soil Erosion and Agricultural Sustainability. PNAS, 104, 13268-13272.

[13] Tilman, D., Cassman, K.G., Matson, P.A., Naylor, R. and Polasky, S. (2002) Agricultural Sustainability and Intensive Production Practices. Nature, 418, 671-677. 
[14] Bender, S.F., Wagg, C. and Van der Heijden, M.G.A. (2016) An Underground Revolution: Biodiversity and Soil Ecological Engineering for Agricultural Sustainability. Trends in Ecology \& Evolution, 31, 440-452.

[15] Thiele-Bruhn, S., Bloem, J., de Vries, F.T., Kalbitz, K. and Wagg, C. (2012) Linking Soil Biodiversity and Agricultural Soil Management. Current Opinion in Environmental Sustainability, 4, 523-528.

[16] LaCanne, C.E. and Lundgren, J.G. (2018) Regenerative Agriculture: Merging Farming and Natural Resource Conservation Profitably. PeerJ, 6, e4428.

[17] Harrison, R.B., Footen, P.W. and Strahm, B.D. (2011) Deep Soil Horizons: Contribution and Importance to Soil Carbon Pools and in Assessing Whole-Ecosystem Response to Management and Global Change. Forest Science, 57, 67-76.

[18] Amundson, R. and Biardeau, L. (2018) Soil Carbon Sequestration Is an Elusive Climate Mitigation Tool. PNAS, 115, 11652-11656.

[19] Kladivko, E. (2015) Cover Crops for Modern Cropping Systems. https://ag.purdue.edu/soilandwater/cover-crops/managing-cover-crops-cover-crops -for-modern-cropping-systems

[20] Blanco-Canqui, H., Shaver, T.M., Lindquist, J.L., Shapiro, C.A., Elmore, R.W., Francis, C.A. and Hergert, G.W. (2015) Cover Crops and Ecosystem Services: Insights from Studies in Temperate Soils. Agronomy Journal, 107, 2449-2474.

[21] Dick, W.A. (1983) Organic Carbon, Nitrogen, and Phosphorus Concentrations and $\mathrm{pH}$ in Soil Profiles as Affected by Tillage Intensity. Soil Science Society of America Journal, 47, 102-107.

[22] Billings, S.A. and Ballantyne IV, F. (2013) How Interactions between Microbial Resource Demands, Soil Organic Matter Stoichiometry, and Substrate Reactivity Determine the Direction and Magnitude of Soil Respiratory Responses to Warming. Global Change Biology, 19, 90-102.

[23] Fae, G.S., Sule, R.M., Barker, D.J., Dick, R.P., Eastridge, M.L. and Lorenz, N. (2009) Integrating Winter Annual Forages into a No-Till Corn Silage System. Agronomy Journal, 101, 1286-1296.

[24] Sokol, N.W. and Bradford, M.A. (2019) Microbial Formation of Stable Soil Carbon Is More Efficient from Belowground than Aboveground Input. Nature Geoscience, 12, 46-55.

[25] NRCS (2014) Soil Organic Matter, in Soil Health-Guides for Educators. USDA, Washington DC.

[26] USDA (2014) 2012 Census of Agriculture; South Carolina State and County Data (AC-12-A-40). NASS, Washington DC.

[27] Gruver, J.B. (2007) Impact of Management and Texture on Soil Organic Matter Fractions North Carolina State University. 1-77.

[28] Soil Survey Staff, N.R.C.S. USDA (2016) Web Soil Survey. https://websoilsurvey.sc.egov.usda.gov/

[29] Roncoli, C. (2006) Ethnographic and Participatory Approaches to Research on Farmers' Responses to Climate Predictions. Climate Research, 33, 81-99.

[30] Hansen, J.W. (2002) Realizing the Potential Benefits of Climate Prediction to Agriculture: Issues, Approaches, Challenges. Agricultural Systems, 74, 309-330.

[31] Hammer, G., Hansen, J., Phillips, J., Mjelde, J., Hill, H., Love, A. and Potgieter, A. (2001) Advances in Application of Climate Prediction in Agriculture. Agricultural Systems, 70, 515-553.

[32] Weber, E.U. (2010) What Shapes Perceptions of Climate Change? Wiley Interdis- 
ciplinary Reviews. Climate Change, 1, 332-342.

[33] Lorenz, K. and Lal, R. (2018) Soil Carbon Stock. In: Carbon Sequestration in Agricultural Ecosystems, Springer, Cham, 39-136.

[34] Monger, H.C., Kraimer, R.A., Khresat, S., Cole, D.R., Wang, X. and Want, J. (2015) Sequestration of Inorganic Carbon in Soil and Groundwater. Geology, 43, 375-378.

[35] Wu, H., Guo, Z., Gao, Q. and Peng, C. (2009) Distribution of Soil Inorganic Carbon Storage and Its Changes Due to Agricultural Land Use Activity in China. Agriculture, Ecosystems and Environment, 129, 413-421.

\section{Supplementary}

Table S1. Compiled soil test organic matter values from single-event samples throughout SC by soil texture, as defined by the Soil Web Survey [28]. As soil texture becomes heavier, a protective effect on organic matter occurs, reflected by consistent increases in OM with texture from light to heavy. Sample data shown here is not indicative of OM levels achieved through regenerative management practices. The samples included in this large dataset include a range of management strategies from conventional to regenerative and are only indicative of general trends in soil texture properties related to OM.

\begin{tabular}{cccc}
\hline & Soil Texture & No. of Samples & OM \\
\hline Sand & 92 & 1.2 \\
& Loamy Fine Sand & 664 & 1.7 \\
Light...Heavy & Loamy Sand & 358 & 1.8 \\
& Sandy Loam & 313 & 2.2 \\
& Fine Sandy Loam & 619 & 2.6 \\
Loam & 109 & 3.6 \\
\hline
\end{tabular}

